
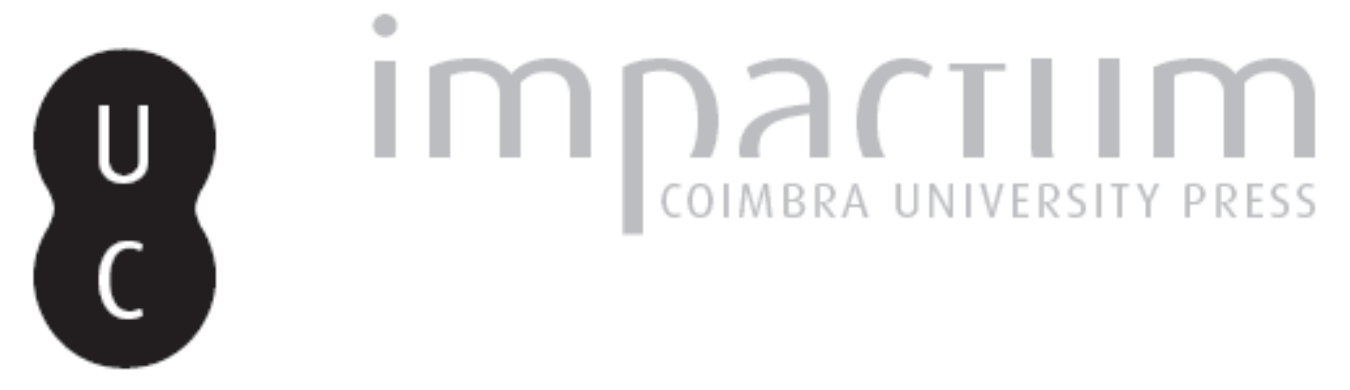

\title{
Homossexualidade feminina na Antiguidade? Ensaio em torno dos trabalhos de Sandra Boehringer
}

Autor(es): $\quad$ Leite, Letticia Batista Rodrigues

Publicado por: Sociedade Brasileira de Estudos Clássicos

URL persistente:

URI:http://hdl.handle.net/10316.2/37154

DOI:

DOI:http://dx.doi.org/10.14195/2176-6436_26-2_12

Accessed : $\quad$ 26-Apr-2023 13:57:04

A navegação consulta e descarregamento dos títulos inseridos nas Bibliotecas Digitais UC Digitalis, UC Pombalina e UC Impactum, pressupõem a aceitação plena e sem reservas dos Termos e Condições de Uso destas Bibliotecas Digitais, disponíveis em https://digitalis.uc.pt/pt-pt/termos.

Conforme exposto nos referidos Termos e Condições de Uso, o descarregamento de títulos de acesso restrito requer uma licença válida de autorização devendo o utilizador aceder ao(s) documento(s) a partir de um endereço de IP da instituição detentora da supramencionada licença.

Ao utilizador é apenas permitido o descarregamento para uso pessoal, pelo que o emprego do(s) título(s) descarregado(s) para outro fim, designadamente comercial, carece de autorização do respetivo autor ou editor da obra.

Na medida em que todas as obras da UC Digitalis se encontram protegidas pelo Código do Direito de Autor e Direitos Conexos e demais legislação aplicável, toda a cópia, parcial ou total, deste documento, nos casos em que é legalmente admitida, deverá conter ou fazer-se acompanhar por este aviso.

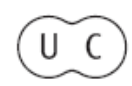




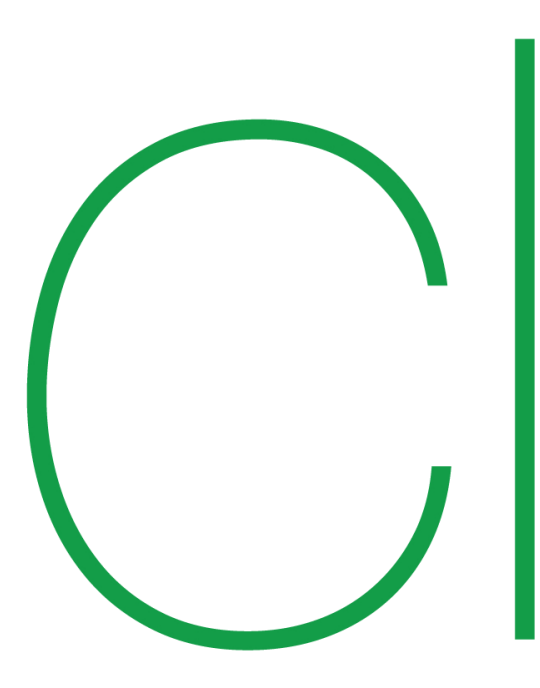

revista brasileira de estudos clássicos
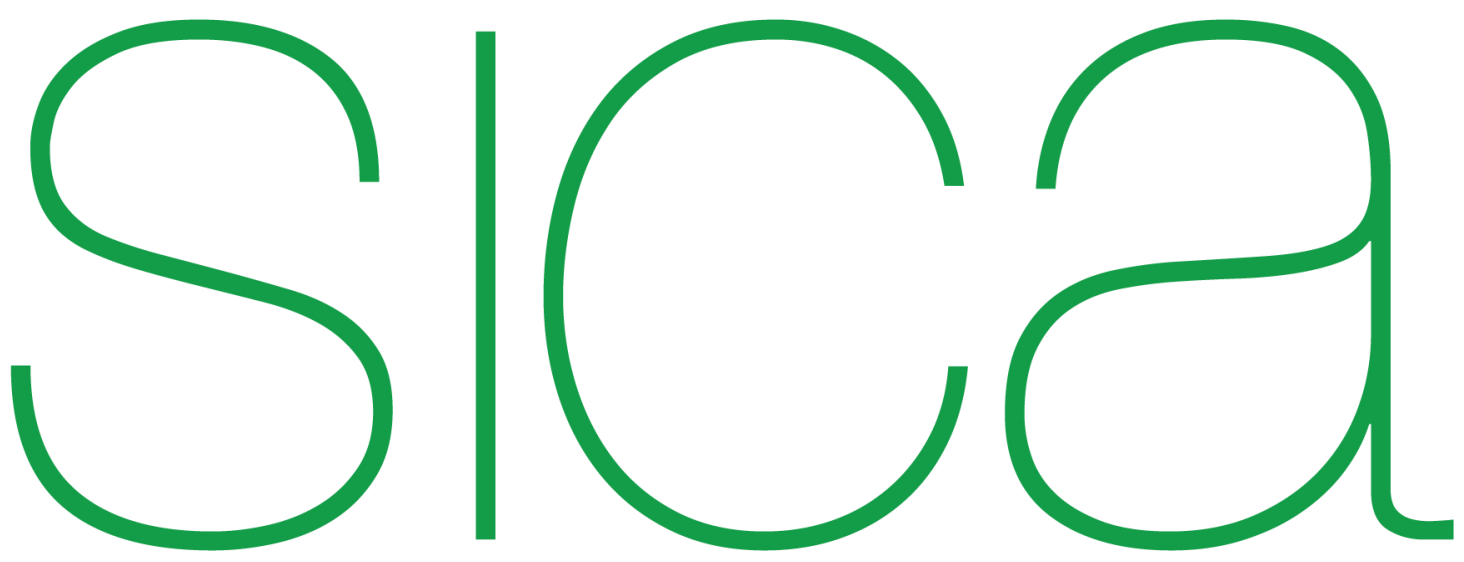

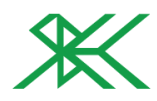

y

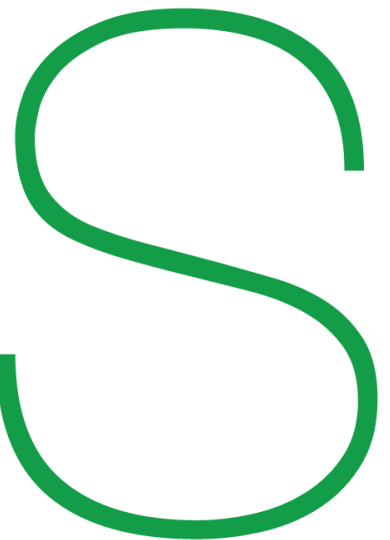




\section{HOMOSSEXUALIDADE FEMININA NA ANTIGUIDADE? ENSAIO EM TORNO DOS TRABALHOS DE SANDRA BOEHRINGER}

\author{
Letticia Batista Rodrigues Leite*
}

$\mathrm{L}$ uc Brisson e Sandra Boehringer abrem o verbete "Grèce antique" (Grécia antiga), que compóe o Dictionnaire seguinte assertiva:

Do século VIII a.C. à Roma Imperial (II d.C.), nunca existiu na língua grega termos que correspondessem à homossexualidade ou à heterossexualidade. Os gregos jamais elaboraram nem pensaram uma categoria sexual que englobasse indistintamente homens e mulheres de todos os meios sociais, tendo por característica comum o fato de sentirem atração por pessoas do mesmo sexo ${ }^{1}$.

No entanto, pelo menos, e sobretudo nos últimos 30 anos, no âmbito dos Estudos Clássicos, alguns são os títulos ${ }^{2}$ em que o substantivo "homossexualidade" aparece. As justificativas, claro, são variadas e encontram-se relacionadas com as perspectivas de abordagem adotadas pelo respectivo(s) autor(es) ou autora(s) dos trabalhos em questão. Isto pode e, ao meu ver, deve ser verificado caso a caso, porém não é meu objetivo aqui repertoriar ou mesmo fazer um balanço de cada um desses registros. Como deixa explícito o título do presente ensaio bibliográfico, a proposta aqui é tratar de "homosexualidade feminina", e mais espificamente, deste tema no âmbito dos trabalhos desenvolvidos pela pesquisadora Sandra Boehringer.

S. Boehringer, professora da Université Marc-Bloch de Strasboug, é a autora do primeiro trabalho inteiramente ${ }^{3}$ dedicado ao tema dos amores entre mulheres na Antiguidade grega e romana, ou melhor, ao estudo dos discursos, das representaçóes acerca de relaçóes eróticas e/ou amorosas entre mulheres: L'homosexualité féminine dans l'Antiquité grecque et romaine (Homossexualidade feminina na Antiquidade
*Université Paris 1 -

Panthéon Sorbonne

1. Boehringer, S. et Brisson, L., "Grèce Antique ", dans TIN, L.-G. (dir.), Dictionnaire de l'homophobie, Paris, PUF, 2003, p. 199 : Depuis le VIII s. avant J.-C. jusquà l'époque romaine impériale (II' s. après J.-C.), il n'a jamais existé en langue grecque de termes signifiant homosexualité ou hétérosexualité. Les Grecs n'ont jamais élaboré ni pensé une catégorie sexuelle qui engloberait indistinctement hommes et fermmes de tous milieux sociaux ayant pour caractéristique commun d'être attirés par les personnes de même sexe. (Todas as traduçóes, salvo indicaçáo contrária, são de minha autoria e inteira responsabilidade).

2. Cito aqui, como exemplo, apenas alguns trabalhos: Dover, K. J., Greek homosexuality, Londres, Duckworth, 1978. Traduzido em português por Luís Sérgio Krausz, $A$ Homossexualidade na Grécia Antiga, 1 ed., São Paulo, Nova Alexandria, 1994. Halperin, D. M., One hundred years of homosexuality: And others essays on Greek love, New York, Routledge, 1990. Sergent, B., L'homosexualité dans la mythologie grecque, Paris, 1984 et L'homosexualité initiatique dans l'Europe ancienne, Paris, 1986.

3. Antes, disso, alguns pesquisadores e pesquisadoras haviam dedicado parte dos seus trabalhos para falar destas relaçôes. Cf., entre outros: Calame, C., Les Choeurs de jeunes filles en Grèce archä̈que, I Morphologie, fonction religieuse et sociale, II Alcman, Rome, Edizioni Dell'Ateneo \& Bizarri, 1977. Dover, K. J., "Women and Homosexuality", 1978, p. 171-184. Cantarella, E., Secondo natura, Rome, Riuniti, 1988. Hallett, J. P., "Female Homoeroticism and 
the denial of roman reality in Latin literature", Yale Journal of Criticism 3.1, 1989, p. 209-227. Halperin, D. M., "The first homosexuality?" [1997], How to do the history of homosexuality, Chicago, The University of Chicago Press, 2002, p. 48-80. Rabinowitz, N. and Auanges, L. (éd.), Among Women. From the Homosocial to the Homoerotic in the Ancient World, Austin, University of Texas Press, 2002. Ernoult, N., "L'homosexualité féminine chez Platon", Revue française de psychanalyse 1, 1994, p. 207-218.

4. Boehringer, S., L'Homosexualité féminine dans l'Antiquité grecque et romaine, Paris, Les Belles Lettres, 2007.

5. Cf. entre outros: Brisson,

L., "Bisexualité et médiation en Grèce ancienne ", Nouvelle Revue de psychanalyse 7 , 1973, p. 27-48. sexe incertain. Androgynie et hermaphroditisme dans L'Antiquité gréco-romaine, Paris, Les Belles Lettres, 1997. , "Le Banquet de Platon comme document sur les comportements sexuels et leur représentation sociale ", dans

L.G.-Tin (éd.), Homosexualités. Expression : répression, Paris, Stock, p. 49-62.

6. Cf. entre outros: Calame, C. $1977 . \_$Le récit en Grèce ancienne. Énonciation et représentation des poètes, Paris, Belin, 1986.

7. Cf. entre outros: Dupont,

F., Linvention de la littérature. De l'ivresse grecque an texte latin, Paris, La découverte, 1994. Dupont, F. et Éloi, T., L'érotisme masculin dans la Rome antique, Paris, Belin, 2001.
Grega e Romana $)^{4}$. Livro publicado pela reconhecida editora Les Belles Lettres, em 2007, e que apresenta os resultados da sua tese de doutorado, orientada por Luc Brisson - ele mesmo autor de inúmeros trabalhos acerca das sexualidades antigas 5 . A defesa de doutorado de S. Boehringer ocorreu no ano de 2003, na École des Hautes Études en Sciences Sociales de Paris. Na ocasião, o título do trabalho apresentado era L'homosexualité féminine dans le discours antique: les relations sexuelles et amoureuses entre femmes dans la construction culturelle et les représentations littéraires des catégories sexuelles grecques et romaines (A homossexualidade feminina no discurso antigo: as relações sexuais e amorosas entre mulheres na construção cultural e as representaçôes literárias das categorias sexuais gregas e romanas). Título que apresentava de forma mais explícita o fato de que neste e em outros estudos, a pesquisadora está preocupada em evidenciar, através de suas análises propostas, que as noçóes de sexualidades tratam-se de construçóes socias. Portanto, suas práticas, as categorizaçóes que se encontraram relacionadas ou náo às mesmas, e suas respectivas representaçóes variam, uma vez que mudamos de contexto temporal, social, enfim, de contexto histórico. Mas não só.

S. Boehringer preocupa-se também em ler e interpretar seus textos de uma perspectiva também ela antropológica. $\mathrm{Na}$ esteira dos trabalhos desenvolvidos, entre outros, por Claude Calame ${ }^{6}$ e Florence Dupont ${ }^{7}$, a estudiosa cuida em precisar às suas leitoras e leitores as implicações relacionadas às "mise en forme" de cada um dos discursos textuais e pictóricos que analisa. Dito de outro modo, ela preocupa-se com as consequências relacionadas às pragmáticas dos discursos construídos em um dado contexto histórico, e portanto, social, em que os autores e seu público se inserem. Isto quer dizer que S. Boehringer leva em conta não apenas o "formato", o gênero discursivo escolhido, mas sobretudo as formas por meio das quais cada um dos autores considerados se valerá das convençôes relacionadas aos mesmos. Ademais, S. Boehringer encontra-se sempre atenta aos objetivos visados pelos autores, uma vez que optam por construir este discurso visando muito provavelmente, a priori, determindos "efeitos" no seu público. Vale ainda dizer que a autora procura sempre considerar o lugar que os discursos enfocados ocupam no conjunto das 
obras dos respectivos autores estudados, assim como os possíveis diálogos intertextuais/inter-discursivos que porventura os mesmos estabeleçam com outros textos/ discursos.

Dito isto, voltemos nossa atenção à presença do substantivo "homosexualidade" em ambas as versões de título escolhidos pela autora. Pois, se por um lado S. Boehringer deixa claro que parte do pressuposto de que:

$\mathrm{Na}$ Antiguidade greco-romana, náo existe equivalente algum à noção moderna de sexualidade. No sentido que nós a entendemos atualmente - mutatis mutandis -, a sexualidade designa as práticas sexuais reais, mas também os desejos náo concretizados, os fantasmas confessos ou não, e, de modo geral, a totalidade do percurso sexual de uma pessoa assim como sua atitude frente a este percurso. A sexualidade contemporânea é parte constitutiva da identidade psicológica de um indivíduo. $\mathrm{Na}$ Antiguidade, um indivíduo náo tem sexualidade, ele exerce algumas práticas. Na Grécia, falamos de $\dot{\alpha} \phi \varrho o \delta i ́ \sigma \iota \alpha$ para fazer referência aos "prazeres sexuais", e, em Roma, fala-se às vezes de "coisas de Vênus", mas com maior frequência de coito, de união sexual. O indivíduo náo se constitui pessoalmente pelo seu percurso sexual: na Grécia e em Roma, não "somos" sexualmente, mas "fazemos" sexualmente

Não obstante, por outro lado, a autora ainda assim defende, justifica e precisa a sua escolha e o seu uso do termo, da noção de "homossexualidade". Ela afirma:

Neste estudo, os termos de "relações homossexais" e de "homossexualidade" serão utilizados no sentido de "relaçôes sexuais entre pessoas do mesmo sexo", e não como termos designando uma categoria de pessoas que se reconhecem enquanto tais, que possuem uma cultura e reivindicaçôes comuns (aspecto sobretudo implicado pela expressão "gays e lésbicas"). Esta escolha trata-se de uma espécie de comodidade (recorrer sem cessar a perífrases deixaria o texto pesado), mas também implica uma forma de realismo (por "relaçóes entre pessoas do mesmo sexo", entendemos de todo modo "relação homossexual", e de toda maneira essas expressóes têm hoje uma conotaçấo categorizante) 9 .
8. Boehringer, S., 2007, p. 28-29: Dans L'Antiquité gréco-romaine, il n'existe aucun équivalent de la notion moderne de sexualité. Dans le sens où nous l'entendons actuellement - mutatis mutandis -, la sexualité désigne les pratiques sexuelles réelles, mais aussi les désirs non concrétisés, les fantasmes avoués ou non, et, de façon générale, la totalité du parcours sexuel d'une personne ainsi que son attitude face à ce parcours. La sexualité contemporaine est constitutive de l'identité psychologique d'un individu. Dans L'Antiquité, un individu n'a pas de sexualité, il se livre à des pratiques. En Grèce, on parle des à $\phi \rho o \delta i \sigma \iota \alpha$ pour désigner les "choses de la jouissance sexuelle ", et, à Rome, on parle parfois des "choses de Vénus", mais plus souvent de coüt, d'union sexuelle. L'individu ne se construit pas par son parcours sexuel: en Grèce et en Rome, on n'est pas sexuellement, on "fait" sexuellement.

9. Boehringer, S., 2007, p. 27 : Dans cette étude, les termes de "relations homosexuelles " et d' " homosexualité " seront utilisés dans le sens de "relations sexuelles entre personnes de même sexe ", et non comme désignant une catégorie de personnes se reconnaissant comme telles et qui ont une culture et des revendications communes (aspect davantage impliqué par l'expression "gays et lesbiennes"). Ce choix est une affaire de commodité (recourir sans cesse à des périphrases alourdit le texte), mais aussi une forme de réalisme (dans "relation entre personnes de même sexe", nous entendons de toutes façons "relation homosexuelle", et quoique en soit, ces expressions ont toujours pour nous une connotation catégorielle). 
10. Foucault, M. $L a$ volonté de savoir, Histoire de la sexualité, vol. 1., Paris Gallimard, 1976.

L'usage des plaisirs, Histoire de la sexualité, vol. II, Paris, Gallimard, 1984(a).

Le souci de soi, Histoire de la sexualité, vol. III, Paris, Gallimard, 1984(b).

11. Boehringer, S., 2007, p. 10.

12. Esta crônica, intitulada "Broutons; genres; pois chiches", foi gentilmente compartilhada comigo por S. Boehringer. Visto que, conforme assinalado, o mesmo foi retirado da rede três dias depois da sua publicação.
Não por acaso, o livro conta com prefácio escrito pelo pesquisador e professor David M. Halperin, cujos trabalhos - tais quais os de S. Boehringer - inscrevem-se numa espécie de continuidade aos trabalhos em torno da "sexualidade", realizados pioneiramente por Michel Foucault, a partir da segunda metade da década de $1970^{10}$. As abordagens de S. Boehringer, e de D. M. Halperin, para além do fato de tratarem das práticas (homo)sexuais na Antiguidade, partilham a oposiçáo de M. Foucault a uma perspectiva essecialista em torno das noçóes de sexualidades. Consequentemente, estes pesquisadores constroem uma história em que seu suposto objeto de partida: a noção de "sexualidade", é sistematicamente desmontado, feito em estilhaços, ausentado em prol da emergência de outras possibilidades de se conceber os agentes praticantes de/e sujeitos aos prazeres. É, portanto, para este paradoxo inerente ao projeto foucaultiano de uma história da sexualidade que D. M. Halperin aponta, ao enfatizar que apesar do que pode deixar supor, 'esta história não presume a existência de uma entidade chamada 'sexualidade' que seria o objeto estável de uma investigação histórica através de diferentes períodos e culturas ${ }^{11}$.

Entretanto, esta concepção encontra ainda hoje uma forte oposição. Fato este que justifica, em parte, a polêmica recepção que envolveu o trabalho de $S$. Boehringer, quando da sua publicação, no final de outubro 2007, pela respeitada editora Belles Lettres. Controvérsia, aliás, lançada de forma inusitada, pelo presidente do comitê de vigilância ("comité de surveillance") da editora, Michel Desgranges que curiosamente ademais, era presidente da Belles Lettres na época em que o manuscrito do livro de S. Boehringer foi aceito para publicação.

No dia 16 de novembro de 2007, encontrava-se na página de abertuta do site da Belles Lettres, uma crônica em torno do livro recém lançado de $S$. Boehringer, assinada por M. Desgranges ${ }^{12}$. Texto ao longo do qual o autor tece considerações nada elogiosas a Foucault - a quem, para dar um exemplo do tom da crônica, ele se refere como um adepto do "first-fucking", - para em seguida atacar o seu projeto, a seu ver absurdo, de se pretender escrever uma história sobre um "fait de nature": a sexualidade. Nesta perspectiva, 
sua leitura do trabalho de $S$. Boehringer não poderia ser outra que extremamente negativa. Perspectiva que, aliás, Desgranges deixa explícita logo de início, ao referir-se ao livro que avalia como uma obra "de dames" -, nascida que é, nas suas palavras, da conjugaçáo démodé do gender studies (que ele considera como "propaganda feminista") e da história da sexualidade. E, para não dizer mais de um texto permeado de referências às supostas práticas sexuais entre mulhereres - ali transformadas em figuras de crítica ao trabalho da S. Boehringer -, destaco apenas que Desgranges encerra sua crônica desmerecendo a pesquisadora de forma pouco elegante. $\mathrm{O}$ cronista vale-se de termos abertamente irônicos na sua referência à autora, defenida por ele em termos de "auteuse" e "professeuse". Uma vez que, do ponto de vista de M. Desgranges, S. Boehringer tornava-se professora às custas de um trabalho pouco, ou nada, merecedor de créditos.

Esta crônica - ademais enviada pela mailing-list da editora para mais de 20 mil pessoas -, seria retirada do site apenas três dias depois, após solicitação formal por parte $S$. Boehringer ${ }^{13}$. Assim, acerca disto, mas também para além disso, os debates em torno do trabalho de S. Boehringer continuariam: sejam eles veiculados por parte de artigos lançados pela imprensa ${ }^{14}$, seja por intermédio de revistas acadêmicas $^{15}$. Neste último âmbito, vale destacar, ainda que brevemente, a resenha assinada pela pesquisadora $\mathrm{Da}$ nielle Gourevitch, e publicada pela revista Latomus, cerca de dois anos depois ${ }^{16}$. Texto no qual os apontamentos críticos reiteram as perspectivas presentes, anos antes, na crônica de M. Desgranges. D. Gourevitch, aliás, nada mais faz que retomar pontos de suas posiçóes já manifestas em outras leituras críticas relativas a outros trabalhos ${ }^{17}$. Posiçōes que, em linhas gerais, vão no sentido de acusar de falta de profissionalismo e objetividade, os trabalhos emprendidos por pesquisadores que assumem uma postura militante (e, manipuladora) - como, ao seu ver, é o caso do livro de S. Boehringer. Postura política que, de resto, D. Gourevitch repudia e acusa de estar presente "por trás" dos gender studies e dos chamados "gays and lesbians studies". Duas aréas de estudos que a autora expressamente filia às instituições norte-americanas, sem no entanto esquecer-se de dirigir
13 Sandra Boehringer relatou-me (assim como gentilmente deume acesso ao e-mail de resposta recebido) que, ao escrever para a diretora da Belles Lettres,

Caroline Noirot, assinalando seu incômodo relativo ao texto, a mesma respondeu desculpando-se, porém dizendo que não teria notado nada de incômodo no que se refere ao conteúdo desta crônica "escrita num tom livre”. Não obstante, em seguida, C. Noirot, enviou um e-mail coletivo à mailing-list da editora, com o objetivo de dissipar qualquer mal entendido relativo à posição da mesma. Pois, ela esclarece, a Belles Lettres jamais teria aceito publicar um trabalho cuja qualidade julgasse questionável. Para tanto, C. Noirot cita um trecho presente na elogiosa crítica ao livro, escrita por Romain Brethes, intitulada "Épouses et concubines", publicada em Le Point, 8 novembre 2007, disponível em: http://www.lepoint.fr/ culture/2007-11-08/epouses-etconcubines/249/0/209167.

14. Destaco: artigo publicado pelo Le Monde des livres, no dia 07 de dezembro de 2007 , intitulado "Bons sens et mauvais genre", assinado por Jean Birnbaum, e que trouxe um comentário crítico a respeito da referida crônica de Desgranges. Esta mesma mesma publicação trouxe, ainda, uma resenha do livro de S. Boehringer, assinada por L.-G. Tin: "Amours féminines. Sandra Boehringer analyse

l'homosexualité antique".

15. Resenha de Ormand, K., American Journal of Philology 134, 2013, p. 163-166.

16 Resenha de Gourevitch, D., Latomus 69, 2010, p. 223-225.

17. Cf. Gourevitch, D., "La sexualité de l'Antiquité. Essai à propos de publications récentes ", Antiquité Classique 68, 1999, p. 331-334. Texto citado e criticado por S. Boehringer, 2007, p. 26. 
18. Cf. Gourevitch, D., 1999, p. 331. A autora abre seu texto dizendo acerca de M. Foucault: “(...) embora Foucault tenha feito tudo para se desvirilizar, ele tinha

o grave defeito de ser um

homem e, portanto, não pode ir até o fim" ((...) Foucault, encore quil fit tout pour se déviriliser, avait le grave défaut d'être un homme et ne pouvait donc aller jusqu'au bout).

19. Cf.: Lear, A. and Altman, M., "The unspeakable vice of the Americans", Iris, The

Newsletter of the Lambda Classical Caucus, Fall, 2010.

Disponível em: http:// eugesta.recherche.univ-lille3. $\mathrm{fr} / \mathrm{PDF} /$ Altman-Lear_ article_from_Iris_on_S. $\% 20$

Boehringer.pdf. Acesso: 29/06/2013.

20. Albertini, P., « Histoire", dans TIN, L.-G. (dir.), 2003, p. 215-218:

21 Albertin, P., 2003, p. 215 : Jusqu'à une date tout à fait récente, l'homosexualité n'était pas un sujet légitime pour les historiens. Plusieurs facteurs concouraient à ce mépris : d'une part, la longue prééminence $d u$ politique prédisposait peu les historiens à s'intéresser aux conduites privés (tout au plus évoquait-on les "gồts contre nature ", réels ou supposés, de tel ou tel grand personnage); d'autre part, les universitaires étaient censés partager l'horreur des honnêtes gens devant pareille abomination ([...]

"quiconque se risquait à sintéresser de trop près au corpus documentaire, craignait d'être soupçonné de sympathies douteuses, comme sil cherchait dans le comportement des Grecs une justification à la levée críticas de ordem pouco acadêmica a, entre outros, $M$. Foucault, que ela apresenta como espécie de figura paterna destes domínios de estudo ${ }^{18}$.

Apresentado este pequeno balanço inicial em torno das perspectivas gerais que fundamentam os trabalhos de $S$. Boehringer, assim como as críticas aos mesmos ${ }^{19}$, - e antes de apresentar pontos mais precisos que aparecem no conjunto da obra desta pesquisadora -, destaco por fim, algumas breves e precisas observaçóes feitas pelo historiador Pierre Albertin. Visto que o autor, logo na abertura do seu verbete "História", presente no já citado Dictionnaire de l'Homophobie ${ }^{20}$, declara:

Até bem recentemente, a homossexualidade não era tida pelos historiadores como um assunto legítimo. Diversos fatores contribuíam para este desprezo: de um lado, a longa proeminência do político pouco predispunha os historiadores a se interessarem pelas condutas privadas (eram sobretudo evocados os gostos "contra a natureza", reais ou supostos de tal ou tal grande personagem); por outro lado, supunha-se que os universitários partilhavam o horror das pessoas honestas frente à tamanha abominação ([...] alguem que se arriscasse a se interessar com muita proximidade a este corpus documental, temia ser suspeito de simpatias duvidosas, como se procurasse no comportamento dos gregos uma justificativa para a suspensão das proibiçóes no tocante aos homossexuais presentes na Europa da primeira metade do século XX) ${ }^{21}$.

Consideraçáo que faço aqui, como forma de sublinhar o fato de que as ausências, os rumores e barulhos historiográficos em torno das (homo)sexualidades, - e, particularmente, em torno da homossexualidade feminina -, possuem eles também uma longa e complexa história. Narrativa que, de resto, encontra-se intimamente atrelada aos contextos em que as discursos historiográficos são enunciados. E, ao meu ver, os trabalhos de S. Boehringer possuem, entre outras, a virturde de estarem atentos a toda esta multiplicidade de relaçóes.

\section{Sexo, gênero e (homo)seXualidades na Antiguidade: aLgumas CONTRIBUiçóes de SANDRa BoEHringer:}

Se a homossexualidade constitui-se em tema tardio no âmbito da historiografia, no entanto a aréa de Estudos Clássicos parece ter primazia reconhecida no trato da temática. 
Aspecto que aliás, P. Albertin não deixa de destacar ao longo do seu supracitado verbete. Ao fazê-lo, porém, ele ressalta: 'É no campo da história antiga, e, particularmente, da história grega, que o tabu foi primeiramente rompido, não obstante, isto se deu em benefício de uma exegese estritamente homofóbica' ${ }^{\prime 22}$. Assim, seria sobretudo a partir dos anos 1970, com a eclosão de movimentos sociais que englobam: o (re)aparecimento dos movimentos feministas e as organizaçóes dos primeiros movimentos LGBT's, com a progressiva descriminalização e despatologização da homossexualidade, que a temática começa a ser retomada a partir de perspectivas outras.

É, pois no final da década de 1970 , que será publicado o primeiro trabalho inteiramente dedicado ao tema, no âmbito da Antiguidade: Greek Homossexuality, de Kenneth J. Dover (1978). Além disso, não é excessivo mencionar ainda uma vez, a emergência, dois anos antes, do projeto de escrita de uma História da Sexualidade, levado a cabo, na França, por M. Foucault - e que continuaria em curso até a primeira metade da década seguinte. Especialmente porque, o segundo e terceiro volumes da série voltaram-se para a Antiguidade, e nestes a influência dos trabalhos de K. J. Dover é explícita.

É relevante sublinhar, ainda, que o objetivo de K. J. Dover era tratar não apenas da homossexualidade masculina, mas também da homossexualidade feminina, assim como das perspectivas femininas acerca da primeira. E é destes últimos dois aspectos que o autor pretende tratar em uma quinzena de páginas que compóe apenas uma parte do terceiro capítulo do seu livro. Parte esta entitulada: "Women and Homosexuality". Não por acaso K. J. Dover abre seu capítulo justificando tal brevidade:

O fato de que a homossexualidade feminina e a atitude das mulheres com relação à homossexualidade masculina possam ambas serem discutidas em uma parte de um capítulo, reflete a escassez de escritoras e de artistas no mundo grego, assim como o silêncio quase total dos escritores e dos artistas sobre o assunto ${ }^{23}$.

Ora, os trabalhos de S. Boehringer - aliás duramente criticados por explorar em demasia tamanho silêncio -, efetivamente não infirmam esta observação inicial e geral de K. J. Dover. Entretanto, na medida em que a pesquisadora explora com esmero os discursos em que as representaçóes de relaçóes entre mulheres aparecem, ela também procura entender des interdits qui frappaient encore les homosexuels dans l'Europe du premier $X X^{e}$ s.).

22. Albertin, P., 2003, p. 216 : C'est dans le champ de l'histoire ancienne et notamment de l'histoire grecque que le tabou fut levé le plus tôt, mais au bénéfice d'une exégèse strictement homophobe. Vale assinalar que para além da exegese homofóbica, e que de modo geral se caracteriza pela busca de dessexualizar a relação homossexual masculina, transformando-a em relação espiritual; o autor cita, ainda, como contraexemplo, o livro A problem in Greek ethics, escrito pelo professor de Oxford John Addigton, e publicado em 1883. Livro cuja recepção foi bastante problemática e profissionalemente consequente para o autor.

23. K. J. Dover, 1978, p. 171: That female homosexuality and the attitude of women to male homosexuality can both be discussed within one part of one chapter reflects the paucity of women writers and artists in the Greek world and the virtual silence of male writers and artists on these topics. 
24. Trabalho que é fruto da tese defendida em 1979, de autoria da historiadora Marie-Jo Bonnet, realizada sob a orientação de Michèlle Perrot. Este trabalho foi publicado pela primeira vez em 1981, sob o título Un choix sans équivoque, e será reeditado em 1995 com o nome de Les Relations amoureuses entre les femmes du XVI au $X X^{e}$ siècle.

25. Refiro-me à disciplina oferecida por Françoise Gaspard e Didier Eribon, de 1998 à 2004, na École des Hautes Études en Sciences Sociales.

26. Cf.: Boehringer, S., 2007a, p. 66-70, 143-147.

27. Cf.: Boehringer, S.,

"Sexe, genre, sexualité : mode d'emploi (dans

l'Antiquité) ", Kentron 21, 2003, p. 83-110.

Disponível em :http:// www.unicaen.fr/puc/ecrire/ revues/kentron/kentron21/

k2104boehringer.pdf. Acesso: 30/06/2013.

"Le genre et la sexualité. État de lieux et perspectives dans le champ des études anciennes ", Lalies 32, 2012, p. 145-167.

28. S. Boehringer, avec la collaboration de L.-G. Tin, Homosexualité. Aimer en Grèce et à Rome, Paris, Les Belles Lettres, 2010, p. 279-280. os fatores que fazem com que, a partir do chamado período clássico grego (V-IV a.C.), a sociedade grega e, mais tarde, a sociedade romana antigas, - ambas, no entanto, profícuas na produção de representaçóes, - optam quase (e, sobretudo em comparação às demais manifestaçóes amorosas-sexuais) que por calar-se no que se refere às estas relaçóes/práticas.

Porém, antes de expor alguns dos pontos trabalhados por $S$. Boehringer, quer-se aqui sublinhar previamente outros fatores conjunturais. O primeiro deles é a diferença de quase 30 anos que separa a publicação da obra de K. J. Dover da publicação da tese de $S$. Boehringer. Interessante é notar ainda, que no contexto acadêmico francês, se apenas em 1981 fora publicado o primeiro trabalho cujo tema central em pauta era a homossexulidade feminin ${ }^{24}$; somente bem mais tarde ainda, em 1998, teve lugar, pela primeira vez no âmbito universitário, a oferta de uma disciplina inteira e explicitamente dedicada a tratar da questáo das homossexualidades ${ }^{25}$.

Feitas estas observaçôes, tornam-se ainda menos anódinas as contribuiçóes representadas pelos artigos e demais trabalhos de S. Boehringer. Pesquisas feitas não apenas em torno e a partir dos discursos (textuais e iconográficos ${ }^{26 .}$ ) relativos à homossexualidade feminina, mas também acerca das categorias usadas pelos antigos, que nos permitem ou não, ou até certo ponto, falar e instrumentalizar noçôes tais quais sexo, gênero e (homo)sexualidade ${ }^{27}$. As análises de S. Boehringer impressionam igualmente pela extensão do período e tipos de representaçóes analisadas. Vale, portanto, ressaltar, que não se pretende aqui, em medida alguma, dar conta em detalhe dos diversos aspectos por ela discutidos, mas apenas destacar alguns pontos.

Desta diversidade dá claro testemunho a reunião de documentos apresentados e brevemente comentados, por S. Boehringer, ao longo do livro Homosexualité. Aimer en Grèce et à Rome. Coletânea que traz ao final um "Addendum. Les relations sexuelles entre fermmes, un parcours de lecture", por meio do qual a pesquisadora pretende disponibilizar às leitoras e leitores interessados, uma espécie de itinerário que os guiará mais facilmente na busca específica pelas representaçóes antigas das relaçóes entre mulheres. Percurso este que, vale destacar, traz listado mais de 30 referências ${ }^{28}$.

Dentre estas constam, evidentemente, as primeiras representaçóes que nos chegaram, e que trazem, cada uma a sua maneira, manifestaçôes discursivas do erotismo entre 
mulheres, quer seja: os fragmentos poéticos amorosos atribuídos a Alcman e a Safo. Ao tratar destes dois distintos universos enunciativos, - de cujas respectivas particularidades, insisto, não pretendemos tratar aqui -, S. Boehringer ressalta, sobretudo, um importante traço comun a estes discursos no que se refere ao homoerotismo feminino que enunciam (ou sugerem, como é o caso do polêmico fragmento de Anacreonte, que a pesquisadora também discute nesta primeira parte $\left.{ }^{29}\right)$ : a ausência de qualquer condenação moral ao mesmo. Constatação que, ademais, corrobora as conclusões já apresentadas anos antes por C. Calame - como reconhece a própria $\mathrm{S}$. Boehringer -, no estudo em que este analisa os discursos amorosos veiculados, entre outros, pela poesia grega arcaica. Neste sentido, C. Calame afirma que: 'procurar traçar uma distinção determinante, no âmbito da expressão amorosa grega arcaica, entre relaçóes heterossexuais e homossexuais, não tem definitivamente sentido algum' ${ }^{30}$.

No que se refere ao período clássico, as representaçóes produzidos são, por sua vez, menos abundantes. O que parece já apontar para uma espécie de "hors-champ", dentre as categorias sexuais antigas, que as relaçóes entre mulheres parecem constituir no âmbito dos discursos produzidos pelas sociedades gregas e romanas antigas. Assim, no que se refere à iconografia, se para este período ela é abundante no que tange às representaçóes homoeróticas masculinas, S. Boehringer conclui que, partindo do quase completo silêncio das imagens quanto às relaçôes entre mulheres, pode-se conjecturar que 'a sociedade grega gosta de ser vista e se ver como um mundo no qual as mulheres não fazem amor' ${ }^{31}$. Já no plano discursivo filosófico, tais representaçôes só reapareceriam no século IV a.C., no âmbito de dois textos de Platão: $O$ Banquete ${ }^{32}$ e As Leis $^{33}$. Em ambos as representaçóes destas relaçóes - ademais distintas, uma vez que aparecem dentro de economias textuais bem diferentes - não são em si negativas, apesar de explicitamente interditas no âmbito de As Leis, graças a sua esterilidade. S. Boehringer destaca ainda, o fato de que suas representaçóes se diferenciam claramente do tratamento dado às relaçóes homoeróticas masculinas; pois, se no que tange a esta última existem traços de uma regulamentação social quanto ao que convém e o que não convém a cada um dos parceiros: $\varepsilon$ $\alpha$ -

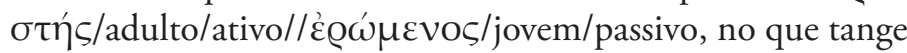

29. Fr. $358($ PMG $)=$ fr. 13 (Gentili). Cf. Boehringer, S., 2007, p. 60-66.

30. CALAME, C., L'Éros dans la Grèce antique, Paris, Belin, 1996, p.71 : chercher à tracer une distinction déterminante dans le domaine de l'expression amoureuse en Grèce archaïque entre relations hétérosexuelles et relations homosexuelles n'a en définitive aucun sens.

31. Boehringer, S., 2007 , p. 157 : Le silence des images sur les relations entre femmes nous permet de savoir que la société grecque aime être vue et aime à se voir comme un monde où les fermmes ne font pas l'amour entre elles.

32. 191d-192a.

33. I 636b1-d4 ; 836c2-6. 
34. Boehringer, S., 2007a,

p. 91-141.

35 Antologia Palatina V, 207.

36. Boehringer, S., 2007 , p.175-205.

37. Heroides, XV, 1-20, 201-206.

38. Odes, II, 13, 24-25.

39. Boehringer, S., 2007,

p. 223.

40. Metamorfoses, II, 409-440 e IX, 714-763. Boehringer, S., "Circulez, il n'y a rien à voir. Le sexe d'Iphis dans les Métamophoses d'Ovide ", Ktéma 38, 2013, p. 347-358.

41. Para uma análise das versóes deste mito cf.: Boehringer, S., 2007, p. 71-88. às relações entre mulheres, não há sinal algum que aponte para semelhante dissimetria que socialmente regulamentaria estas relaçôes ${ }^{34}$.

Quanto ao período Helenistico, S. Boehringer nos apresenta a análise dos poucos traços discursivos que testemunham acerca desta modalidade amorosa: o epigrama atribuído a Alsclepiades de Samos, e que remonta ao século III a.C ${ }^{35}$, é um destes $^{36}$. Epigrama que segundo sua análise - contrariamente à perspectiva apresentada pela maior parte dos comentadores-, se condena a relação entre mulheres, a faz não em si e como reflexo de uma suposta condenação predominante na época do autor, mas claramente a enuncia assim, antes como expressão de um lamento e condenaçáo de seu narrador amorosamente preterido. Ademais, ela destaca o fato de que aí, ainda uma vez, temos a representação de duas mulheres que, se parceiras, em nada são assimétricas. Depois deste testemunho, até a segunda metade do século I a.C. representação alguma, textual ou iconográfica fará mencão de relaçóes entre mulheres.

A sociedade romana antiga, por sua vez, retomará a temática reiteradas vezes, dentre estas destacaremos algumas. Neste sentido, merecem destaque as mençóes presentes em Ovídio, a começar pela $15^{\circ}$ carta que compóe as suas Heroi$\operatorname{des}^{37}$; uma vez que nestas, pela primeira vez após Horácio ${ }^{38}$, Safo e os amores entre mulheres serão evocados. Menção que, ademais, ao contrário de grande parte dos comentadores, S. Boehringer não entende como necessariamente portadora de um julgamento moral negativo, mas antes como um recurso retórico eficaz, instrumentalizado por Ovídio, de modo a valorizar o amor por Faon presentemente evocado pela sua narradora: Safo. Feitas estas observaçóes, S. Boehringer entretanto náo deixa de destacar o fato de que, em Roma, é através da figura de Safo que emerge o discurso acerca das relaçóes sexuais e amorosas entre mulheres ${ }^{39}$. No que tange ao discurso ovidiano relativo aos amores entre mulheres, a pesquisadora também destaca e analisa sua aparição quando esse autor, em sua Metamorfoses ${ }^{40}$, ao retomar dois mitos: o mito de Calisto ${ }^{41}$ e o mito de Ifis, opta por retomá-los em suas respectivas versões em que esta modalidade amorosa é, em alguma medida, evocada. Feita a análise destas diferentes menções, S. Boehringer chega portanto à conclusão de que, se esta modalidade erótico-amorosa reemerge em Ovídio, ela é discursivamente 
posta à parte das demais, para em seguida ser negada como possibilidade erótica de fato realizável. Interpretação convincente, não apenas por dar conta de explicar a maneira pela qual a narradora ovidiana Safo, ao invocar seus amores por mulheres, os relega ao passado de modo a reforçar sua escolha amorosa presente; tal leitura também explica a ausência da mesma nos Amores, assim como na Arte de Amar de Ovídio.

S. Boehringer faz, pois, questão de sublinhar que, de acordo com suas análises, as primeiras mençóes explicitamente negativas com relação aos enlaces erótico-amorosos entre mulheres, poderão ser lidas apenas em outros textos. Ora, no começo do I século a.C., é que teríamos o aparecimento de um termo latino cuja função é designar aquelas que praticam esta modalidade erótica: tribas $^{42}$. Termo que em grego (

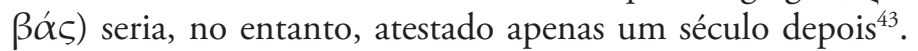
Vocábulos estes que, nos contextos em que aparecem, designam de diferentes maneiras, mas em todo caso, uma prática que aparece como desviante, ou no mínimo particular, no que se refere às normas sociais aceitas. Assim, não por acaso é com esta conatação que o mesmo aparecerá quando da sua primeira evocação relacionada à poetisa Safo, num comentário que remonta ao começo do século III d.C. ${ }^{44}$

Destaco, por fim, as análises que $S$. Boehringer empreenderá dos discursos satíricos em que aparece o tema das relaçôes entre mulheres. Trata-se dos textos de: Marcial ${ }^{45}$, Pseudo-Luciano ${ }^{46}$, Petrônio ${ }^{47}$, Juvenal ${ }^{48}$ e Luciano ${ }^{49}$, textos em que cenas e/ou referências abertas à relaçóes entre mulheres aparecem, e nos quais seus respectivos enunciadores as representam como condenáveis. S. Boehringer, no entanto, sublinha a importância de contextualizar tais discursos, de modo a entender a função que cada um destes discursos condenatórios desempenha dentro dos enunciados em que aparecem. Ademais, ela destaca o forte jogo de intertextos que, em diferentes medidas, cada um destes autores coloca em jogo em suas respectivas mise en acte de tais personagens.

S. Boehringer examinará ainda, um conjunto de discursos antigos de caráter científico, em que as relaçóes entre mulheres são mencionadas ${ }^{50}$. Neste rápido e preciso exame a pesquisadora destaca ainda uma vez, certos efeitos que preconceitos e pressupostos modernos exercem sobre as interpretaçóes de textos antigos relacionados ao tema. Neste sentido,
42. Termo cuja primeira atestação, ambas no acusativo plural (tribadas) é difícil de definir dentre: Fedro, Fábulas, IV, 16 ; Sêneca, Controvérsias, I, 2, 23. Excertos analisados em: Boehringer, S., 2007, p.261-271.

43. Para uma lista da ocorrência destes termos cf. Boehringer, S., 2007, p. 272.

44. Commentum in Horati Epistulas, I, 19, 28, 3.

45. Epigramas, VII, 67 e

70. Cf. : Boehringer, S., "Le corps de Philaenis ou les ravages de sexe dans les Épigrammes de Martial ", dans Bodiou, L. et Audebert, M. S. (dir.),

Corps outragés, corps ravagés. Regards croisés de l'Antiquité au Moyen Age, Turnhout, Brepols, 2011, p. 231-248.

46. Amores, 27-29. Boehringer, S., "Comparer l'incomparable. La sunkrisis érotique et les catégories sexuelles dans le monde gréco-romain ", dans Perreau, B. (dir.), Le choix de l'homosexualité. Recherches inédites sur la question gay et lesbienne, Paris, EPEL, 2007, p. 39-56.

47. Satíricon, 67, 11-13.

48. Sátiras, II, 47-54.

49. Diálogo das Cortesâs, V. Boehringer, S., « Pratiques érotiques antiques et questions identitaires. Ne pas pendre Lucien au mot (Dialogues des courtisanes, V), CLIO (Histoire, Femmes et Sociétés) 30, 2010a, p. 19-52.

50. Artemidoro, Sobre a interpretação dos sonhos, I, 80. Anônimo, Tratado de fisiognomonia, 85. Caelius Aurelianus, Sobre doenças agudas e crônicas, 4, 9, 132-133. 
51. Boehringer, S., "Ces monstres de femmes. Topique des thaumata dans les discours sur l'homosexualité féminine aux premiers siècles de notre ère ", dans P. Mudry, O. Bianchi et O. Thévenaz (éd.), Mirabilia. Conceptions et représentations de l'extraordinaire dans le monde antique. (Actes du colloque international, Lausanne, 20-22 mars 2003), Echo 4, Bern, Peter Lang, 2004, p. 75-98. as análises de S. Boehringer destacam-se por infirmar uma relação há muito defendida por grande parte dos comentadores modernos como estando presente neste textos: a de que uma má formação física relacionada a uma masculinização, o crescimento exarcebado do clitóris, caracterizaria as mulheres que fazem amor com outras mulheres. Não obstante, se a pesquisadora reiteradamente destaca ao longo de suas análises esta ausência direta de uma assimilação por parte dos antigos - diferentemente de grande parte dos comentadores modernos - entre mulheres que amam mulheres e aspectos a priori pertencentes ao gênero e práticas sexuais masculinas, ela não deixa de chamar atenção para a insistente presença de topos e de um léxico próprios à descrição do "maravilhoso" (mirabilia, $\theta \alpha u ́ \mu \alpha \tau \alpha)$, nos discursos produzidos no período imperial ${ }^{51}$.

Enviado em julho de 2013 Aprovado em outubro de 2013. 